\title{
The Relationship between Carbohydrates and Flower Bud Hardiness among Three Forsythia Taxa
}

\author{
Cindy L. Flinn ${ }^{1}$ and Edward N. Ashworth ${ }^{2}$ \\ Department of Horticulture, Purdue University, West Lafayette, IN 47907 \\ Additional index words. Forsythia $\times$ intermedia 'Spectabilis', Forsythia $\times$ intermedia 'Lynwood', F. suspensa, starch, \\ raffinose, stachyose, thermal analysis, supercooling
}

\begin{abstract}
The accumulation of total soluble sugars (TSS) and starch and their relationship to flower bud hardiness were studied in three Forsythia taxa: Forsythia xintermedia 'Spectabilis', Forsythia xintermedia 'Lynwood', and $F$. suspensa. Taxon hardiness was based on the mean temperature at which low temperature exotherms (LTEs) occurred during thermal analysis. Ethanol-extracted soluble sugars were quantified with anthrone, and starch was enzymatically digested and quantified with Trinder reagent. Qualitative changes in sugar content were determined with high-performance liquid chromatography and co-chromatography of authentic standards. Quantitative and qualitative changes in sugar content, similar for the three taxa, were observed in conjunction with fluctuations in flower bud hardiness, although neither TSS nor starch were correlated with mean LTE temperature. TSS was higher in acclimated than nonacclimated buds. However, after deacclimation began, sugars continued to increase with mean LTE temperature. Buds lacked starch except for a brief period during deacclimation. Galactose, stachyose, raffinose, and an unidentified carbohydrate were positively correlated with hardiness $(P=0.005,0.001,0.005$, and 0.001 , respectively $)$.
\end{abstract}

The flower buds of many woody species undergo deep supercooling to avoid freeze injury during winter (Andrews and Proebsting, 1987; Ashworth, 1990; George and Burke, 1977; Graham and Mullin, 1976; Pierquet et al., 1977; Quamme, 1974, 1986; Rajashekar, 1989; Warmund and George, 1990). Among these species, which include several Forsythia taxa (Ashworth, 1990; data from parallel study), supercooling ability was confirmed by the occurrence of low-temperature freezing events or exotherms (LTEs) during a controlled freezing test. These LTEs coincided with the temperature at which lethal injury occurred within developing floral organs and therefore have been used as estimators of flower bud hardiness.

The development, maintenance, and subsequent dissolution of supercooling ability appear to be linked to the frequency of occurrences of daily subzero temperatures (Andrews and Proebsting, 1987; Quamme, 1983). However, freezing temperatures can be lethal when they occur in the form of a sudden, midwinter freeze or a late spring frost subsequent to the loss of supercooling ability. Many physiological and biological changes are apparently involved in hardiness regulation including carbohydrate metabolism (Alden and Hermann, 1971; Kandler and Hopf, 1980), protein synthesis, gene expression (Guy, 1990), and alterations to membranes (Steponkus, 1984). Hardiness-related alterations in carbohydrate status have been studied in a wide range of plant species (Kandler and Hopf, 1980). Although a causal relationship has not been established, development of plant hardiness is typically associated with an increase in total soluble sugars (TSS) (Alden and Hermann 1971; Kandler and Hopf, 1980). In leaves and bark tissues of most plants, this increase arises concomitant with the hydrolysis of starch reserves. (Alberdi et al., 1989; Ashworth et al., 1993; Kandler and Hopf, 1980; Khalafalla

Received for publication 28 June 1994. Accepted for publication 6 Dec. 1994. Journal paper no. 14287 of the Purdue Univ. Agricultural Experiment Station. We thank Vicki Stirm and Suzanne Cunningham for technical assistance and Robert Joly and Mike Foley for reviewing the manuscript. The cost of publishing this paper was defrayed in part by the payment of page charges. Under postal regulations, this paper therefore must be hereby marked advertisement solely to indicate this fact. 'Graduate research assistant. Presently with the Johnston County Extension Service, North Carolina State Univ., Smithfield, N.C.

${ }^{2}$ Associate professor; to whom reprint requests should be addressed. and Palzkill, 1990; O'Neill, 1983), although some exceptions have been reported (Alden and Hermann, 1971; Ristic and Ashworth, 1993). However, hardiness-related changes in the carbohydrates of flower buds have not been documented for species other than peach [Prunus persica (L) Batsch] (Durner, 1989; Durner and Gianfagna, 1991; Lasheen and Chaplin, 1977; Layne and Ward, 1978). In those studies, the accumulation of TSS in flower buds differed from that observed in foliage and stem tissues in two respects: 1 ) acclimated flower buds were devoid of starch (Layne and Ward, 1978) and 2) the strong correlation between seasonal changes in hardiness and TSS that had been observed in leaves and stems was not observed in flower buds. In leaves and stems, levels of TSS typically declined with hardiness during deacclimation, whereas TSS in peach flower buds continue to increase through full bloom (Layne and Ward, 1978). However, some qualitative changes within TSS were highly correlated with bud hardiness (Lasheen and Chaplin, 1977) and were similar to those reported in leaves (Hinesley et al., 1992; Khallafala and Palzkill, 1990) and stems (Alden and Hermann, 1971; Ashworth et al., 1993; Kandler and Hopf, 1980). The sugars most often correlated with hardiness among all of these tissues were sucrose, raffinose, and stachyose, although concentrations varied among species and among plant tissues.

To determine whether hardiness-related changes in carbohydrates observed in peach flower buds are typical of reproductive buds in other species, we examined these relationships in the buds of three Forsythia taxa. The genus Forsythia, like Prunus, is comprised of numerous supercooling taxa (Ashworth, 1990; data from a parallel study). Although similar in hardiness, these taxa were differentially killed by a severe mid-winter freeze in 1991. Flower buds of $F$. intermedia 'Spectabilis' and $F$. suspensa survived to bloom the following spring while those of $F$. intermedia 'Lynwood' did not. To determine if carbohydrate composition of acclimated buds can differentiate among taxa with respect to hardiness limitations, this study was designed to answer the following questions: 1) What seasonal relationship, if any, exists among soluble sugars, starch, and hardiness in flower buds? 2) What individual carbohydrates comprise the soluble sugar fractions of the three taxa? and 3) Are any of these carbohydrates correlated with flower bud hardiness? 


\section{Materials and Methods}

Plant material. Terminal segments of the current season's growth of F. suspensa (Thunb.) Vahl., Forsythia $\times$ intermedia 'Spectabilis' (Koehne), and Forsythia xintermedia 'Lynwood' (G.E. Peterson) were collected from plantings on the Purdue campus in West Lafayette, Ind. Material was harvested during Winter 1992-93 at the following stages of hardiness: nonacclimated (9 Sept)., acclimated (11 Feb.-21 Mar.), and reacclimated (28 Mar.-9 Apr.). On each date, harvested materials were misted, sealed in plastic bags, and transported to the laboratory packed in ice. Upon arrival, the sealed bags were transferred to $-4 \mathrm{C}$ for a maximum of $2 \mathrm{~h}$.

Thermal analysis. A modification of the thermal analysis procedure described by Ashworth (1990) was used to determine the depth of flower bud hardiness on each date. Leaves and all but one flower bud were removed from twelve 5 -cm stem segments of each taxon. The remaining bud of each stem segment was taped to a 30gauge (0.25-mm-diameter) copper-constantan thermocouple and placed in a stoppered test tube with $0.5 \mathrm{ml}$ water and a chip of ice. The tubes were then cooled at $2 \mathrm{C} / \mathrm{h}$ to $-40 \mathrm{C}$ in a circulating 50 ethanol :50 ethylene glycol (v/v) bath (components from Neslab Instruments, Newington, N.H.). Bud temperatures were recorded every $15 \mathrm{sec}$ with a computer-based data-acquisition program. From resulting thermal profiles, the temperature preceding abrupt spikes in bud temperature were recorded as the LTE temperature. LTE temperatures were averaged for each taxon.

Daily minimum and maximum temperatures during the study were obtained from the Purdue Weather Service, located on campus in West Lafayette. The weather station was located $\approx 2 \mathrm{~km}$ from Forsythia plantings.
Carbohydrate analysis. In preparation for carbohydrate analysis, flower buds were excised from stems, quench frozen in liquid nitrogen, and freeze-dried. Three replicates of 50 lyophilized buds of each taxon on each date were weighed, ground in a Wiley mill to pass through a 60-mesh screen, and stored at $-80 \mathrm{C}$. Fiftymilligram aliquants of each milled replicate, along with an equal weight of polyvinylpolypyrrolidone (Sigma Chemical Co., St. Louis) and $250 \mu \mathrm{l}$ of $10 \mathrm{~mm}$ lactose (internal standard), were extracted with $1 \mathrm{ml} 80 \%(\mathrm{v} / \mathrm{v})$ ethanol for $15 \mathrm{~min}$ and centrifuged at $4000 \times \mathrm{g}$ for $5 \mathrm{rein}$, and the supernatant was decanted. The pellet was extracted two additional times. Supernatants were pooled and brought to a final volume of $10 \mathrm{ml}$ with $80 \%$ ethanol. Total sugars were then measured as glucose equivalents in triplicate replicates of each sample with anthrone (Van Handel, 1968). Portions of extracts were stored at $-80 \mathrm{C}$ for later quantification of individual sugars.

Ethanol-extracted pellets were dried overnight at $80 \mathrm{C}$ and then resuspended in a $50 \mathrm{~mm}$ sodium acetate buffer $(\mathrm{pH}=5.2)$. Starch in the pellets was then digested to glucose by incubating the pellets for $12 \mathrm{~h}$ at $57 \mathrm{C}$ with 400 units $/ \mathrm{ml} \alpha$-amylase and 2 units $/ \mathrm{ml}$ amyloglucosidase in $50 \mathrm{~mm}$ sodium acetate buffer. After centrifugation at $4,000 \times \mathrm{g}$ for $5 \mathrm{~min}$., triplicate aliquots of $200 \mathrm{ml}$ of supernatant from each sample was brought to a final volume of 1 $\mathrm{ml}$ and was quantified with glucose Trinder reagent (Sigma Chemical Co.).

Identification of individual sugars. Qualitative analysis of ethanol-extracted sugars was accomplished by methods described by Ashworth et al. (1993). Briefly, ethanol was evaporated from $0.5 \mathrm{ml}$ extract of each sample. Sugars were redissolved in $1 \mathrm{ml}$ deionized water and filtered through a $0.45-\mu \mathrm{m}$ nylon membrane. Extracts were separated into their component peaks by injecting 25

Table 1. Seasonal changes in flower bud hardiness and carbohydrate components of Forsythia flower buds. Each LTE value represents the mean of 10 replications and each sugar value represents the average of 3 replications.

\begin{tabular}{|c|c|c|c|c|c|c|c|}
\hline \multirow{2}{*}{$\begin{array}{l}\text { Sample } \\
\text { date }\end{array}$} & \multirow[b]{2}{*}{ Taxon } & \multirow{2}{*}{$\begin{array}{c}\text { Mean } \\
\text { LTE } \\
\left({ }^{\circ} \mathrm{C}\right)\end{array}$} & \multicolumn{5}{|c|}{$\begin{array}{c}\text { Sugar } \\
\left(\mathrm{mg} \cdot \mathrm{gm}^{-1} \text { dry } \quad w t\right)\end{array}$} \\
\hline & & & Galactose & Glucose & Fructose & Sucrose & Melibiose \\
\hline \multirow[t]{3}{*}{9 Sept. } & Lynwood & -5.0 & 0.62 & 63.99 & 14.71 & 52.00 & 0.00 \\
\hline & Spectabilis & -5.0 & 0.35 & 54.89 & 6.51 & 40.44 & 0.00 \\
\hline & F. suspensa & -5.0 & 0.31 & 52.60 & 8.07 & 51.25 & 0.00 \\
\hline \multirow[t]{3}{*}{$11 \mathrm{Feb}$} & Lynwood & -20.4 & 6.07 & 74.35 & 30.84 & 2.67 & 6.09 \\
\hline & Spectabilis & -20.6 & 6.20 & 70.56 & 30.48 & 5.14 & 5.36 \\
\hline & F. suspensa & -20.7 & 4.88 & 77.07 & 27.17 & 3.47 & 4.10 \\
\hline \multirow[t]{3}{*}{1 Mar. } & Lynwood & -19.8 & 7.22 & 73.23 & 38.85 & 2.38 & 7.17 \\
\hline & Spectabilis & -20.7 & 6.84 & 62.81 & 39.15 & 1.06 & 6.67 \\
\hline & F. suspensa & -20.4 & 6.93 & 72.15 & 39.35 & 1.39 & 6.66 \\
\hline \multirow[t]{3}{*}{14 Mar. } & Lynwood & -20.1 & 5.47 & 71.87 & 30.34 & 12.69 & 6.29 \\
\hline & Spectabilis & -21.2 & 6.67 & 70.05 & 31.96 & 1.54 & 7.18 \\
\hline & F. suspensa & -20.4 & 4.83 & 62.40 & 31.99 & 19.37 & 5.01 \\
\hline \multirow[t]{3}{*}{21 Mar. } & Lynwood & -17.4 & 6.53 & 71.43 & 21.21 & 0.00 & 6.61 \\
\hline & Spectabilis & -17.9 & 6.45 & 70.81 & 22.90 & 0.21 & 6.84 \\
\hline & F. suspensa & -18.5 & 5.62 & 71.39 & 23.10 & 0.27 & 5.39 \\
\hline \multirow[t]{3}{*}{28 Mar. } & Lynwood & -15.9 & 5.54 & 72.46 & 17.82 & 0.00 & 5.12 \\
\hline & Spectabilis & -14.7 & 5.34 & 72.23 & 18.28 & 0.00 & 5.15 \\
\hline & F. suspensa & -15.6 & 4.77 & 74.09 & 17.65 & 0.00 & 4.09 \\
\hline \multirow[t]{3}{*}{4 Apr. } & Lynwood & -11.7 & 4.59 & 73.90 & 26.44 & 0.00 & 5.19 \\
\hline & Spectabilis & -12.4 & 3.31 & 76.17 & 44.61 & 0.00 & 1.55 \\
\hline & F. suspensa & -10.4 & 4.68 & 75.47 & 23.69 & 0.00 & 4.26 \\
\hline \multirow[t]{3}{*}{9 Apr. } & Lynwood & -5.7 & 3.65 & 68.18 & 46.31 & 0.00 & 2.08 \\
\hline & Spectabilis & -5.5 & 5.37 & 76.53 & 27.42 & 0.00 & 5.01 \\
\hline & F. suspensa & -6.6 & 4.28 & 76.35 & 65.46 & 2.08 & 1.92 \\
\hline
\end{tabular}


$\mu \mathrm{l}$ each sample into a high-performance liquid chromatography (Dionex, Sunnyvale, Calif.) equipped with a pulsed amperomeric detector and a CarboPac PA1 pellicular resin column $(4 \times 250$ $\mathrm{mm})$. Peaks were identified by comparison with retention times of authentic standards of arabinose, galactose, glucose, fructose, sucrose, melibiose, lactose, raffinose, stachyose, and maltose.

\section{Results}

Environmental temperature. No natural freezes occurred before the first collection date. For subsequent collection dates, minimum temperatures below $0 \mathrm{C}$ had occurred. January's daily minimum temperatures ranged from -11 to $2 \mathrm{C}$ and were below $0 \mathrm{C}$

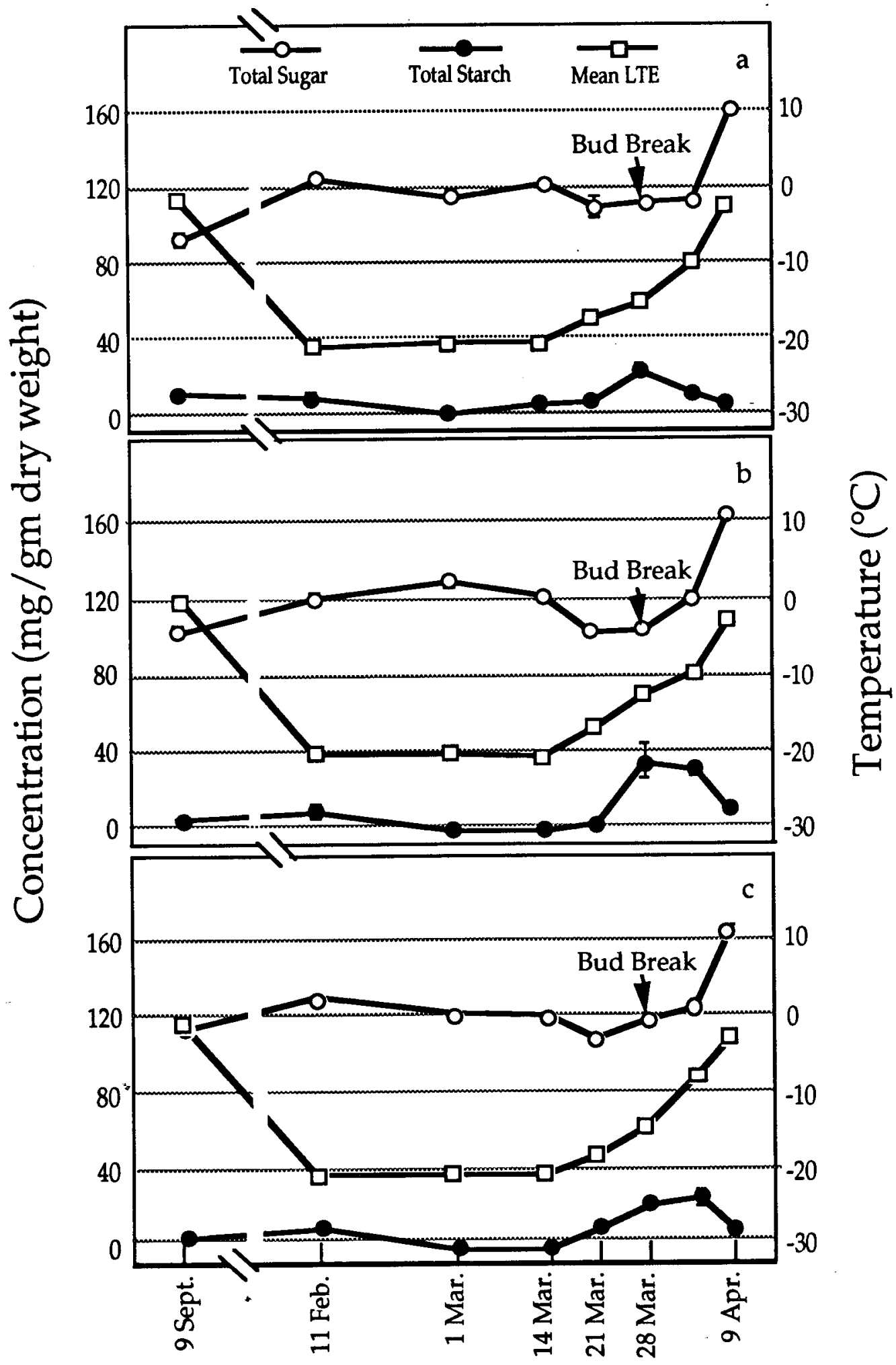

Fig. 1. Seasonal fluctuation of carbohydrate content and cold hardiness of three Forsythia taxa; Carbohydrate values are the average of three replicate assays and mean LTEs are averages of 12 replicates of buds collected during Winter 1992. Error bars indicate the standard deviations. Taxa are Forsythia 'Lynwood' (a), Forsythia 'Spectabilis' (b) and $F$. suspensa (c). Total soluble sugars were not correlated with starch levels $[r=0.084$ (a), 0.401 (b), 0.367 (c)] or with hardiness $[r=0.265$ (a), 0.028 (b), 0.408 (c)]. Starch was not correlated with hardiness either $[r=0.249$ (a), 0.161 (b), 0.303 (c)]. 
on 23 days. Daily minimum temperatures for February were much colder, ranging from -22 to $1 \mathrm{C}$ with a total of 26 days below 0C. A warming trend began in March with daily low temperatures ranging from -11 to $12 \mathrm{C}$ and only 11 days below 0C. B y April, low temperatures ranged from -4 to $14 \mathrm{C}$, with only 5 days below $0 \mathrm{C}$. The winter was punctuated with 2 weeks 'of abnormally warm temperatures of 11 to $16 \mathrm{C}$ beginning on $1 \mathrm{Feb}$.

Flower bud hardiness. Flower bud hardiness, similar among the taxa throughout the season, followed the same trends observed in minimum daily temperatures. The most cold-sensitive buds in the study were collected on 9 Sept., before the first autumn freeze. By 11 Feb., buds had acclimated to about $-20.5 \mathrm{C}$ and remained at that level of hardiness through 14 Mar. Over the next weeks, buds reacclimated with mean LTEs for all three taxa increasing at the rate of 2-4C per week. On the last collection day, 9 Apr., buds were no longer hardy, as was demonstrated by mean LTEs of $-5.7,-5.5$, and -6.6C for 'Lynwood', 'Spectabilis', and F. suspensa (Table 1).

Carbohydrates. Seasonal soluble sugar content was similar among the three taxa. TSS increased from $10 \%, 11 \%$, and $12 \%$ of bud dry weight for 'Lynwood', 'Spectabilis', and $F$. suspensa, respectively (Fig. 1), on 9 Sept. to $\approx 12 \%$ to $13 \%$ of dry weight by 11 Feb., where they remained through 14 Mar. Soluble sugars initially declined during deacclimation, but subsequently increased. At the last sampling, TSS had risen to $\approx 16 \%$ of bud dry weight, the highest levels observed during the study.

The amount of starch in Forsythia flower buds was negligible at the first four sampling dates (Fig. 1). Beginning in mid-March, starch levels rose in all three taxa to a maximum of $\approx 2 \%$ and $4 \%$ ('Spectabilis') bud dry weight. However, by the last sampling date, starch levels had returned to undetectable amounts.

The composition of extracted sugars of Forsythia flower buds, a complex mixture of $>20$ carbohydrates, changed over the course of the study, although compositions were similar among taxa (Table 1). Concentration of sorbitol, myo-inositol, arabinose, galactose, glucose, fructose, sucrose, melibiose, raffinose, and stachyose in flower bud extracts were determined via standard curves of individual components. One carbohydrate was tentatively identified as lactose in preliminary trials. However, subsequent analysis of a lactose-spiked sample revealed the unknown component to be a different carbohydrate with elution times similar to that of lactose. Arabinose, sorbitol, and myo-inositol were relatively stable throughout the season and therefore were precluded from subsequent analyses.

Correlation coefficients calculated for the relationships between individual sugars and TSS, starch, and hardiness revealed that glucose and fructose, which were the predominant sugars throughout the season, were linearly correlated with TSS (P > 0.005) (Fig. 1, Table 2). Although glucose was correlated with hardiness also $\left(F^{\prime}=0.05\right)$, coefficients of the following sugars, listed in order of decreasing concentration, were more significant: galactose, stachyose, a second unidentified carbohydrate, and raffinose $(P=0.005,0.001,0.001$, and 0.005 , respectively). The concentration of the second unidentified carbohydrate, with elution times intermediate to those of melibiose and raffinose, was based on the molecular weight of the trisaccharide raffinose and was present in amounts comparable to stachyose (Fig. 2). Raffinose, stachyose, and this second unknown were present only in acclimated and reacclimating buds. As a molar fraction of identified carbohydrates, their concentrations declined steadily throughout dormancy from a combined maximum of $5 \%$ in February to $0 \%$ by 4 Apr. Differences in mean sugar concentrations of raffinose and stachyose were not significant among taxa. However, on 11 Feb., concentrations of the unknown were highest in buds of 'Lynwood' and 'Spectabilis' and on 1 Mar. in 'Spectabilis'. Sucrose was more abundant in nonacclimated buds than in any other buds, and, like melibiose, was not correlated with hardiness.

\section{Discussion}

Flower bud hardiness is affected by many environmental factors, not the least of which is temperature (Andrews and Proebsting, 1987; Graham and Mullin, 1976; Quamme, 1983). Forsythia flower buds were no exception. Mean LTE temperatures in all three taxa followed trends in daily minimum temperatures. Similar to bud hardiness in sweet cherry (Andrews and Proebsting, 1987), the depth of Forsythia hardiness appeared to be unaffected by a brief period of unseasonably warm temperatures that occurred in February.

The accumulation of soluble sugars during cold acclimation has been observed in a diverse range of plant species (Alden and Hermann, 1971; Kandler and Hopf, 1980). Like peach buds (Layne and Ward, 1978), TSS was higher in acclimated Forsythia buds than in nonacclimated ones (Fig. 1). However, unlike TSS in

Table 2. Matrix of correlation coefficients for hardiness, total carbohydrates, and individual sugars.

\begin{tabular}{|c|c|c|c|c|c|c|c|c|c|c|}
\hline \multirow{2}{*}{$\begin{array}{l}\text { Forsythia } \\
\text { taxon }\end{array}$} & \multicolumn{3}{|l|}{ - } & \multicolumn{5}{|c|}{ Pearson's correlation coefficient $(r)$} & \multirow[b]{2}{*}{ Raffinose } & \multirow[b]{2}{*}{ Stachyose } \\
\hline & $\mathrm{TSS}^{\mathrm{z}}$ & TNS $^{y}$ & Galactose & Glucose & Fructose & Sucrose & Melibiose & Unknown & & \\
\hline \multicolumn{11}{|l|}{ Lynwood } \\
\hline MLTE $^{\mathrm{x}}$ & 0.29 & 0.18 & $-0.82^{* * *}$ & $-0.67^{*}$ & 0.07 & 0.19 & -0.48 & $-0.83^{* * *}$ & $-0.74^{* * *}$ & $-0.84^{* * *}$ \\
\hline TSS & & 0.08 & 0.37 & $0.87^{* * *}$ & $0.92^{* * *}$ & -0.55 & 0.06 & 0.16 & 0.25 & 0.16 \\
\hline TNS & & & 0.04 & 0.27 & -0.27 & 0.18 & -0.01 & -0.38 & -0.59 & -0.47 \\
\hline \multicolumn{11}{|l|}{ Spectabilis } \\
\hline MLTE & -0.10 & 0.25 & $-0.72^{* *}$ & $-0.71^{* *}$ & -0.03 & -0.28 & -0.53 & $-0.84^{* * *}$ & $-0.68 *$ & $-0.83^{* * *}$ \\
\hline TSS & & 0.40 & 0.52 & $0.86^{* * *}$ & $0.74^{* *}$ & -0.58 & -0.27 & -0.04 & 0.01 & 0.08 \\
\hline TNS & & & -0.01 & 0.72 & 0.43 & 0.30 & 0.26 & 0.52 & -0.45 & 0.52 \\
\hline \multicolumn{11}{|l|}{ F. suspensa } \\
\hline MLTE & 0.47 & 0.41 & $-0.76^{* * *}$ & -0.34 & 0.30 & 0.30 & -0.49 & $-0.92^{* * *}$ & $-0.71^{* *}$ & $-0.88^{* * * *}$ \\
\hline TSS & & 0.37 & 0.55 & $0.95^{* * *}$ & $0.96^{* * *}$ & -0.23 & -0.08 & -0.33 & -0.24 & 0.38 \\
\hline TNS & & & 0.22 & 0.51 & 0.20 & -0.44 & -0.31 & -0.53 & -0.55 & $-0.67 *$ \\
\hline
\end{tabular}

${ }^{2}$ Total soluble sugars.

'Total nonsoluble sugars.

${ }^{x}$ Mean LTE temperature.

$*$,**, ***Significant at $P=0.05,0.01$, or 0.005 , respectively. 


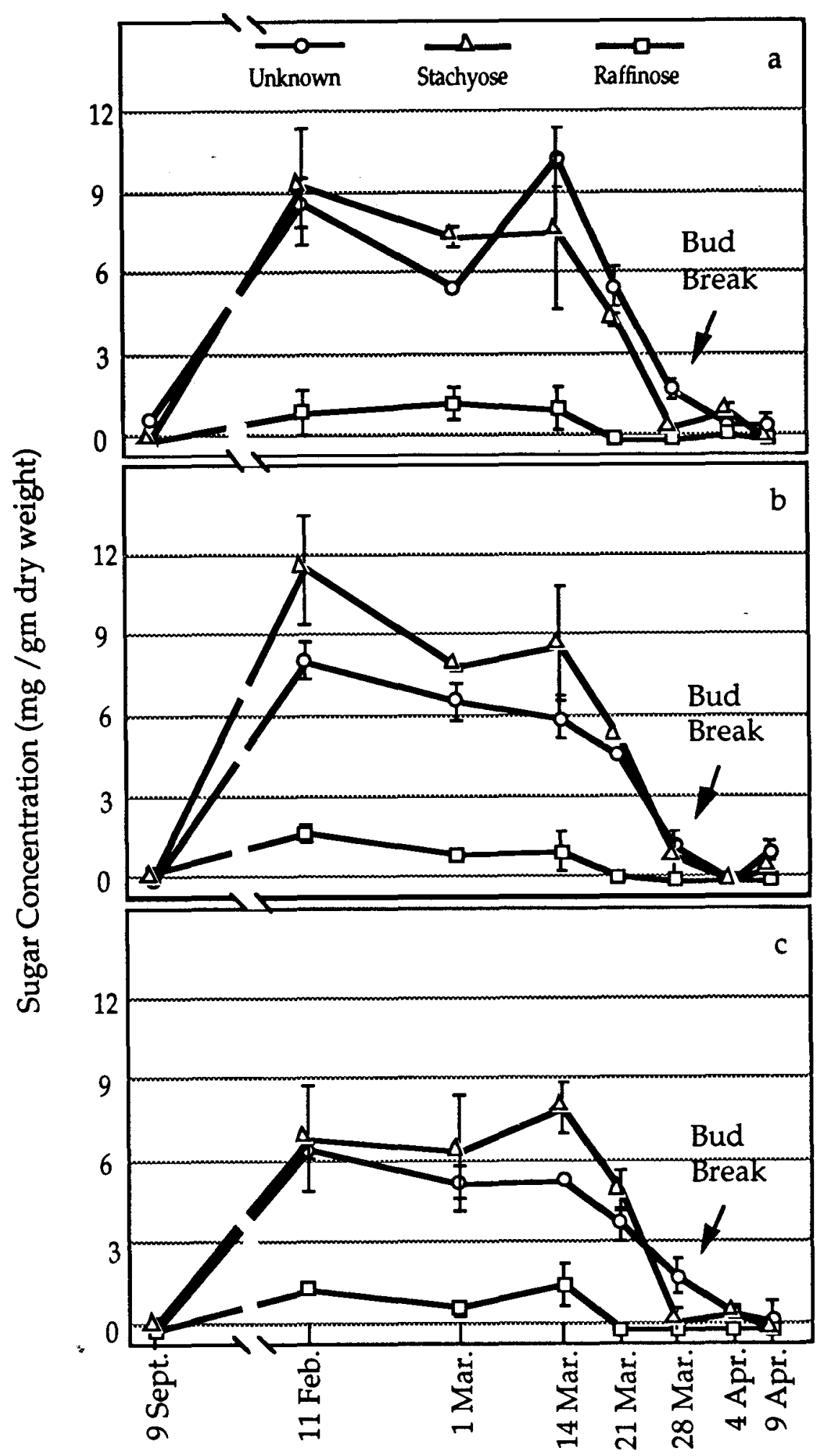

Fig. 2. Seasonal course of individual sugars in buds of three Forsythia taxa. Sugar values are the average of three replicates with error bars indicating standard deviations Taxa are Forsythia 'Lynwood' (a), Forsythia 'Spectabilis' (b) and F. suspensa (c).

leaves and stems of other genera (Alberdi et al, 1989; Alden and Hermann, 1971; Ashworth et al., 1993; Kandler and Hopf, 1980; Khalafalla and Palzkill, 1990; Lasheen and Chaplin, 1977; O’NeilI, 1983), the seasonal changes in TSS among Forsythia taxa buds were not correlated with fluctuations in flower bud hardiness (Table 2). This and the lack of starch in nonacclimated and acclimated buds is also typical of peach flower buds (Layne and
Ward, 1978). Lasheen and Chaplin (1977) concluded that the increase in soluble sugars accompanying acclimation in flower buds had been translocated from other parts of the plant. This also appeared to be the case in acclimated Forsythia buds. However, unlike peach (Layne and Ward, 1978), Forsythia buds were not devoid of starch the whole season (Fig. 1). Simultaneous to a decline in TSS and the onset of deacclimation, carbon partitioning 
apparently switched from soluble sugars to starch. During a subsequent resumption in TSS accumulation, starch was depleted, giving rise to an increase in the molar fraction of monosaccharides as flowers reached full bloom. The physiological significance of this shift in metabolism is unknown.

Glucose and fructose were just 2 of $>20$ carbohydrates that comprised soluble sugars in Forsythia taxa. One as yet unidentified sugar appeared to co-chromatograph with lactose. In view of earlier reports indicating the presence of lactose in the pollen of two of the Forsythia taxa used in the present study (Avigad, 1982; Kuhn and Low. 1949), soluble sugar extracts before and after the addition of lactose as an internal standard were qualitatively compared. The lack of naturally occurring lactose was confirmed by the presence of an additional peak in lactose-spiked samples, although elution times of lactose and this unknown were often $<0.5$ min apart. Although the presence of lactose had been previously refuted (Toba et al., 1991), the presence of a carbohydrate with chromatographic properties comparable to those of lactose was not mentioned. As the results of our study indicate, this unidentified sugar may have been mistakenly identified as lactose in earlier literature (Avigad, 1982; Kuhn and Low, 1949).

The gain and subsequent loss of cold hardiness in overwintering plant tissues have often been linked with similar changes in the concentrations of sucrose, sorbitol, raffinose, and stachyose (Alden and Hermann, 1971; Ashworth et al., 1993; Hinesley et al., 1992; Kandler and Hopf, 1980; Lasheen and Chaplin, 1977). The relationship between the first two sugars and Forsythia flower bud hardiness differed from that observed in peach flower buds (Lasheen and Chaplin, 1977). In the present study, sucrose was lower in nonacclimated than in acclimated buds, and sorbitol levels remained stable during the winter (Table 2; sorbitol data not presented). However, flower bud hardiness was highly correlated not only with raffinose and stachyose, as in peach flower buds (Lasheen and Chaplin, 1977), but also with a second unidentified carbohydrate. Although attempts were made to identify this carbohydrate by comparing its elution times with those of trehalose, mannose, xylose, maltose, and verbascose, it remains unidentified.

The roles that raffinose and stachyose play in plant cold hardiness have not been established, although circumstantial evidence suggests that a physiological role may exist. In Pinus excelsa seedlings, for example, the induction of frost resistance at $20 \mathrm{C}$ by exposure to short-day photoperiods also resulted in the accumulation of raffinose, whereas long day treatments at the same temperature resulted in neither frost resistance nor raffinose accumulation (KandlerandHopf, 1980). The presence of raffinose and stachyose in conjunction with sucrose appears necessary to confer desiccation tolerance to membranes (Hoekstra et al., 1992; Koster and Leopold, 1988; Koster, 1991). These sugars are thought to replace lost water in hydrophilic interactions, reduce toxic concentrations of chaotropic solutes, or provide structural support through glass formation. And since plant tissues undergo a freeze-induced drought as cellular water migrates toward growing extracellular ice crystals, this may be a potential role for raffinose and stachyose in freeze-resistant flower buds as well. In this capacity, even concentrations as small as those observed in acclimated Forsythia buds have been demonstrated to be effective (Koster, 1991).

Transport of photosynthetic assimilates from source tissues to sinks in other parts of the plant is achieved via transport of carbohydrates, which are often family-specific (Dumer, 1989; Durner and Gianfagna, 199 1; Madore, 1990; Mitchell and Madore, 1992). For example, genera of the Rosaceae family translocate carbohydrates in the form of sorbitol (Durner, 1989; Durner and Gianfagna, 1991), while stachyose is the primary transport carbo- hydrate for members of the Lamiaceae family (Madore, 1990; Mitchell and Madore, 1992). Although the sugar composition of Forsythia, a member of the Oleaceae, was unknown before the current study, labeling studies had been conducted with other members of the same family (Kandler and Hopf, 1980). Those studies indicated that sugars in the leaves were transported to stems and roots as raffinose (Kandler and Hopf, 1980). Whether raffinose serves as a transport carbohydrate in Forsythia is not known.

What do the results of this study mean with respect to our original hypothesis that sugar composition could be used to predict hardiness limits of Forsythia taxa? Unfortunately, the lack of significant differences in cold hardiness among the taxa studied precluded a thorough test of the hypothesis. However, correlations between the levels of raffinose, stachyose, and an unknown carbohydrate with cold hardiness indicates that one or a combination of the three might serve as indicators of flower bud hardiness. Even more promising was the observation that the taxon with the largest concentration of this unknown component had the lowest mean LTE temperature, although differences in hardiness were not significant among the taxa. Similar studies conducted on Forsythia taxa with a broader range of flower bud hardiness than those used in the current study would indicate whether this sugar might serve as a selectable marker for cold tolerance.

\section{Literature Cited}

Alberdi, M., L. Meza-Basso, J. Fernandez, D. Rios, and M. Romero. 1989. Seasonal changes in carbohydrate content and frost resistance of leaves of Nothofagus species. Photochemistry 28:759-763.

Alden, J. and R.K. Hermann. 1971. Aspects of the cold-hardiness mechanism in plants. Bet. Rev. 37:37-117.

Andrews, P.K. and E.L. Proebsting. 1987. Effects of temperature on deep supercooling characteristics of dormant and reacclimating sweet cherry flower buds. J. Amer. Soc. Hort. Sci. 112:334-340.

Ashworth, E.N. 1990. The formation and distribution of ice within Forsythia flower buds. Plant Physiol. 92:718-725.

Ashworth, E. N., V.E. Stirm, and J.J. Volenec. 1993. Seasonal variation in soluble sugars and starch within woody stems of Cornus sericea L. Tree Physiol. 13:379-388.

Avigad, G. 1982. Sucrose and other disaccharides, p. 217-347. In: F.A. Loewus and W. Tanner (eds.). Plant carbohydrates. I. Intracellular carbohydrates. Encyclopedia of plant physiology. new series. vol. 13A. Springer-Verlag, Berlin.

Dumer, E.F. 1989. Cryoprotection of reacclimating peach flower buds by ethephon alteration of pistil carbohydrate content. Cryobiology 26:290296.

Dumer, E.F. and T.J. Gianfagna. 1991. Peach pistil carbohydrate and moisture contents and growth during controlled deacclimation following ethephon application. J. Amer. Soc. Hort. Sci. 116:507-5 11.

George, M.F. and M.J. Burke. 1977. Supercooling in overwintering azalea flower buds. Plant Physiol. 59:326-328.

Graham, P.R. and R. Mullin. 1976. The determination of lethal freezing temperatures in buds and stems of deciduous azalea by a freezing curve method. J. Amer. Soc. Hort. Sci. 101:3-7.

Guy, C.L. 1990. Cold acclimation and freezing stress tolerance: Role of protein metabolism. Annu. Rev. Plant Physiol. 41:187-223.

Hinesley, L.E. , D.M. Pharr, L.K. Snelling, and S.R. Funderburk. 1992. Foliar raffinose and sucrose in four conifer species: Relationship to seasonal temperatures. J. Amer. Soc. Hort. Sci. 117:852-855.

Hoekstra, F. A., J.H. Crowe, L.M. Crowe, T. Van Roekel, and E. Vermeer. 1992. Do phospholipids and sucrose determine membrane phase transitions in dehydrating pollen species? Plant Cell Environ. 15:601-606.

Kandler, O. and H. Hopf. 1980. Occurrence, metabolism, and function of oligosaccharides. In: Biochemistry of plants. vol. 3. Academic Press, New York.

Khalafalla, M.S. and D.A. Palzkill. 1990. Seasonal patterns of carbohydrates and proline in jojoba clones that differ in frost susceptibility. 
HortScience 25: 103-105.

Koster, K. 1991. Glass formation and desiccation tolerance in seeds. Plant Physiol. 96:302-304.

Koster, K. and C. Leopold. 1988. Sugars and dessication tolerance in seeds. Plant Physiol. 88: 829-832.

Kuhn, R. and I. Low. 1949. The occurrence of lactose in the plant kingdom. Chem. Ber. 82:479-481.

Lasheen, A.M. and C.E. Chaplin. 1977. Seasonal sugar concentration in two peach cultivars differing in cold hardiness. J. Amer. Soc. Hort. Sci. 102:171-174.

Layne, R.E.C. and G.M. Ward. 1978. Rootstock and seasonal influences on carbohydrate levels and cold hardiness of 'Redhaven' peach. J. Amer. Soc. Hort. Sci. 103:408-413.

Madore, M.A. 1990. Carbohydrate metabolism in photosynthetic and nonphotosynthetic tissues of variegated leaves of Coleus blumei Benth. Plant Physiol. 93:617-622.

Mitchell, D.E. and M.A. Madore. 1992. Patterns of assimilate production and translocation in muskmelon (Cucumis melo L.). Plant Physiol. 99:966-971.

O'Neill, S.D. 1983. Osmotic adjustment and the development of freezing resistance in Fragaria virginiana. Plant Physiol. 72:938-944.

Pierquet, P., C. Stushnoff, and M.J. Burke. 1977. Low temperature exotherms in stem and bud tissue of Vitis riparia Michx. J. Amer. Soc.
Hort. Sci. 102:54-55.

Quamme, H.A. 1974. An exothermic process involved in freezing injury to flower buds of several Prunus species. J. Amer. Soc. Hort. Sci. 99:311-314.

Quamme, H.A. 1983. Relationship of air temperature to water content and supercooling of overwintering peach flower buds. J. Amer. Soc. Hort. Sci. 108:697-701.

Quamme, H.A. 1986. Use of thermal analysis to measure freezing resistance of grape buds. Can. J. Plant Sci. 66:945-952.

Rajashekar, C.B. 1989. Deep supercooling in stem and bud tissues of pecan. HortScience 24:348-350.

Ristic, Z. and E.N. Ashworth. 1993. Changes in leaf ultrastructure and carbohydrates in Arabidopsis thaliana L. (Heyn) cv. Columbia during rapid cold acclimation. Protoplasm 172:11 1-123.

Steponkus, P.L. 1984. Role of the plasma membrane in freezing injury and cold acclimation. Annu. Rev. Plant Physiol. 35:543-584.

Toba, T., S. Nagashima, and S. Adachi. 1991. Is Lactose Really Present in Plants? J. Sci. Food. Agr. 54:305-308.

Van Handel, E. 1968. Direct microdetermination of sucrose. Anal. Biochem. 22:280-283.

Warmund, M.R. and M.F. George. 1990. Freezing survival and supercooling in primary and secondary buds of Rubus spp. Can. J. Plant Sci. 70:893-904. 